\title{
Gated SPECT: What's the ideal method to measure LVEF?
}

\author{
Sum-Che Man · Ernst E. van der Wall • \\ Cees A. Swenne
}

Received: 7 July 2008/ Accepted: 8 July 2008/Published online: 2 September 2008

(C) The Author(s) 2008. This article is published with open access at Springerlink.com

Among the variables that characterize mechanical cardiac performance, left ventricular ejection fraction (LVEF) has attracted broad clinical interest, as various studies have provided ample evidence that LVEF is a major prognostic parameter [1-4]. Also, LVEF is among the selection criteria for device-based anti-arrhythmic or resynchronization therapy [5, 6]. Several imaging techniques allow for the assessment of LVEF, e.g., 2D and 3D echocardiography, gated SPECT, contrast angiography, cardiovascular magnetic resonance imaging (CMR) and computed tomography [7]). In patients with suspected ischemia, a common strategic sequence in which imaging techniques are being utilized is echocardiography, gated SPECT and coronary angiography, the latter frequently combined with or followed by intervention. As these three imaging techniques may all yield LVEF values it is not uncommon in clinical practice to have access to multiple LVEF measurements of the same patient.

If, in one patient, these three LVEF values are available, what would be the measure of preference? The answer to this question depends upon the reliability of the measurement technique and on its proven prognostic value. Whether or not the echocardiogram, gated SPECT and the ventriculogram

S.-C. Man · E. E. van der Wall · C. A. Swenne $(\bowtie)$ Department of Cardiology, Leiden University Medical Center, PO Box 9600, 2300 RC Leiden, The Netherlands e-mail: c.a.swenne@lumc.nl determined during angiography faithfully assess LVEF depends on a large variety of factors: the build of the patient, the technical quality of the equipment, amount of views (monoplane/biplane), quality of the analyzing software/algorithms, the potential for quantitative analysis, and of the operator/analyst being the most important ones [8-13].

Comparison with CMR, an important reference technique often being considered as a gold standard [14-19], can help in getting an impression of the relative accuracy of LVEF as measured by echocardiography, gated SPECT and contrast ventriculography [20-22].

- Jenkins et al. [23] compared serial LVEF values from 2D biplane and 3D echocardiography with serial MRI measurements in patients with prior myocardial infarction. They found that LVEF values measured with $2 \mathrm{D}$ and $3 \mathrm{D}$ echocardiography correlated significantly with MRI; $r=61 \%$ and $86 \%$ for baseline, and $70 \%$ and $82 \%$ for follow-up, respectively. However, when a comparison is made of the serial changes in LVEF, only 3D echocardiography correlated significantly with MRI $(r=58 \%)$.

- In a review article, Sciagrà [24] cites 21 studies in which SPECT- and CMR-determined LVEF values were compared. Correlations measured in these studies ranged between 70 and 94\%; 5 studies report correlations between 70 and $79 \%$, 11 between 80 and $89 \%$ and 5 above $90 \%$. 
- Several studies compared contrast monoplane or biplane ventriculography with CMR [25-28]. Correlation coefficients in these studies ranged from $72 \%$ to $98 \%$.

When realizing that correlations of, e.g., 80 and $86 \%$, roughly stand for $2 / 3$ and $3 / 4$ explained variance, respectively, echocardiography, gated SPECT and contrast ventriculography may yield LVEF values that differ considerably from CMR despite the statistical significance of the linear relationship. However, CMR is not suitable for large scale application in the context of the regular clinical diagnostic procedures for the evaluation of patients with suspected or known ischemic heart disease. Hence, in clinical practice, a certain (considerable?) amount of LVEF imprecision or uncertainty is inevitable.

Mutual comparison of LVEF determined by echocardiography, gated SPECT and contrast ventriculography demonstrates that these measurements contain to a certain extent different information and/ or noise: correlations of $72-75 \%$ in $2 \mathrm{D}$ biplane echocardiography versus gated SPECT [29, 30], 93\% in 3D echocardiography versus gated SPECT [31], $49-93 \%$ in 2D biplane echocardiography versus ventriculography $[12,32,33], 80 \%$ between 3D echocardiography and ventriculography [34] and 69$87 \%$ for gated SPECT versus contrast left ventriculography [32, 35-37] were reported. Hence, potentially, one measurement could bear other diagnostic and prognostic information than the other.

It is the merit of Gimelli et al. [38] to have compared the prognostic value of LVEF determined by echocardiography (single plane), gated SPECT and contrast ventriculography (single plane). The authors found, in a large population of patients with known or suspected ischemic heart disease, a superior predictive value of gated SPECT (resting, not postexercise) LVEF. What can explain this finding? It is well known that systematic differences exist because SPECT may exclude part of the outflow tract [36]. Also, it may well be that the single plane LVEF measurements in the echocardiograms and in the contrast ventriculograms could not compete with the tomographic gated SPECT technique. Finally, the SPECT LVEF calculation is more objective and reproducible due to automated analysis [39].

Gimelli et al. studied a large group of 422 patients with for the larger part an adequate cardiac function.
Ejection fractions below, but also above 50\%, the lower limit of normal in male subjects, are represented in the study group. Possibly (this was not made explicit in their publication), part of the patients had symptoms of overt, stage $\mathrm{C}$, heart failure, but most of the other patients in the study group can be characterized as stage B heart failure (patients with structural heart disease, at risk for heart failure but still without symptoms of this disease [40]), several of them with asymptomatic LV systolic dysfunction and angina pectoris/myocardial infarction.

In a review article [41], Goldberg and Jessup state that the number of stage B heart failure patients with LV systolic dysfunction is four times greater than the number of patients who are in stages $C$ (structural heart disease with prior or current symptoms of heart failure) and D (refractory heart failure requiring specialized interventions) combined. Coronary artery disease is the prevailing etiology of asymptomatic LV systolic dysfunction. In the Framingham study, half of the subjects with asymptomatic LV systolic dysfunction at entry had a previous myocardial infarction versus $2 \%$ of the subjects with a normal $\mathrm{LV}$ function at entry [42]. The prognosis of asymptomatic LV systolic dysfunction was unfavorable: $26 \%$ developed overt heart failure after 5 years of follow-up, and $40 \%$ died (compared to $12 \%$ of the subjects with a normal baseline left-ventricular function). The median survival for subjects with asymptomatic LV systolic dysfunction was only 7.1 years. Similarly alarming numbers were provided by the ECHOES (Echocardiographic Heart of England Screening) study [43], reporting a $69 \%$ five-year survival for asymptomatic LV systolic dysfunction (compared to $93 \%$ for the general population, $62 \%$ for subjects with heart failure but without LV systolic dysfunction, and 53\% for subjects with heart failure and LV systolic dysfunction).

No specific treatment is currently available for patients with asymptomatic LV systolic dysfunction. However, a recent AHA Scientific Statement [44] mentions this group of patients as a main target for further study, because LV systolic dysfunction is the first step in the remodeling process that finally leads to overt heart failure. Research recommendation 4 reads: "Develop appropriate studies to identify and eventually treat asymptomatic individuals with LV dysfunction (stage B) and to prevent its development." 
Most likely, the findings of Gimelli et al. reflect partly the prognosis of stage B heart failure patients. Therefore, it could be worthwhile to carefully monitor patients for cardiac remodeling, possibly by repeated 3D echocardiography [23, 45], after they have been identified as asymptomatic LV systolic dysfunction patients by gated SPECT (of which Gimelli et al. demonstrated prognostic value additional to clinical variables) or, possibly, by a reliable biplane echocardiogram or ventriculogram or by a 3D echocardiogram. A similar study as that by Gimelli et al., in which, in this setting, the prognostic power additional to clinical variables of LVEF determined by gated SPECT is compared with LVEF determined by biplane echocardiography or contrast ventriculography or by $3 \mathrm{D}$ echocardiography would be a logical next step.

Open Access This article is distributed under the terms of the Creative Commons Attribution Noncommercial License which permits any noncommercial use, distribution, and reproduction in any medium, provided the original author(s) and source are credited.

\section{References}

1. Hundley WG, Morgan TM, Neagle CM et al (2002) Magnetic resonance imaging determination of cardiac prognosis. Circulation 106:2328-2333

2. Nelson GR, Cohn PF, Gorlin R (1975) Prognosis in medically-treated coronary artery disease: influence of ejection fraction compared to other parameters. Circulation 52:408412

3. Shah PK, Maddahi J, Staniloff HM et al (1986) Variable spectrum and prognostic implications of left and right ventricular ejection fractions in patients with and without clinical heart failure after acute myocardial infarction. Am J Cardiol 58:387-393

4. Sharir T, Germano G, Kang X et al (2001) Prediction of myocardial infarction versus cardiac death by gated myocardial perfusion SPECT: risk stratification by the amount of stress-induced ischemia and the poststress ejection fraction. J Nucl Med 42:831-837

5. Epstein AE, DiMarco JP, Ellenbogen KA et al (2008) ACC/AHA/HRS 2008 guidelines for device-based therapy of cardiac rhythm abnormalities: a report of the American College of Cardiology/American Heart Association Task Force on Practice Guidelines (Writing committee to revise the ACC/AHA/NASPE 2002 guideline update for implantation of cardiac pacemakers and antiarrhythmia devices): developed in collaboration with the American Association for Thoracic Surgery and Society of Thoracic Surgeons. Circulation 117:e350-e408

6. Vardas PE, Auricchio A, Blanc JJ et al (2007) Guidelines for cardiac pacing and cardiac resynchronization therapy: the task force for cardiac pacing and cardiac resynchronization therapy of the European Society of Cardiology. Developed in collaboration with the European Heart Rhythm Association. Eur Heart J 28:2256-2295

7. Rumberger JA, Behrenbeck T, Bell MR et al (1997) Determination of ventricular ejection fraction: a comparison of available imaging methods. The Cardiovascular Imaging Working Group. Mayo Clin Proc 72:860-870

8. Abidov A, Germano G, Hachamovitch R et al (2006) Gated SPECT in assessment of regional and global left ventricular function: major tool of modern nuclear imaging. J Nucl Cardiol 13:261-279

9. Aurigemma GP, Gaasch WH, Villegas B et al (1995) Noninvasive assessment of left ventricular mass, chamber volume, and contractile function. Curr Probl Cardiol 20:361-440

10. Dodge HT, Sandler H, Baxley WA et al (1966) Usefulness and limitations of radiographic methods for determining left ventricular volume. Am J Cardiol 18:10-24

11. Everaert H, Bossuyt A, Franken PR (1997) Left ventricular ejection fraction and volumes from gated single photon emission tomographic myocardial perfusion images: comparison between two algorithms working in threedimensional space. J Nucl Cardiol 4:472-476

12. McGowan JH, Cleland JG (2003) Reliability of reporting left ventricular systolic function by echocardiography: a systematic review of 3 methods. Am Heart J 146:388-397

13. Schaefer WM, Lipke CS, Standke D et al (2005) Quantification of left ventricular volumes and ejection fraction from gated 99mTc-MIBI SPECT: MRI validation and comparison of the Emory Cardiac Tool Box with QGS and 4D-MSPECT. J Nucl Med 46:1256-1263

14. Bax JJ, Lamb H, Dibbets P et al (2000) Comparison of gated single-photon emission computed tomography with magnetic resonance imaging for evaluation of left ventricular function in ischemic cardiomyopathy. Am J Cardiol 86:1299-1305

15. Langerak SE, Vliegen HW, de Roos A et al (2002) Detection of vein graft disease using high-resolution magnetic resonance angiography. Circulation 105:328-333

16. Slart RH, Bax JJ, van Veldhuisen DJ et al (2006) Imaging techniques in nuclear cardiology for the assessment of myocardial viability. Int J Cardiovasc Imaging 22:63-80

17. Tulevski II, Hirsch A, Sanson BJ et al (2001) Increased brain natriuretic peptide as a marker for right ventricular dysfunction in acute pulmonary embolism. Thromb Haemost 86:1193-1196

18. van Rugge FP, Holman ER, van der Wall EE et al (1993) Quantitation of global and regional left ventricular function by cine magnetic resonance imaging during dobutamine stress in normal human subjects. Eur Heart J 14:456-463

19. van Rugge FP, van der Wall EE, Spanjersberg SJ et al (1994) Magnetic resonance imaging during dobutamine stress for detection and localization of coronary artery disease. Quantitative wall motion analysis using a modification of the centerline method. Circulation 90:127-138

20. Bavelaar-Croon CD, Kayser HW, van der Wall EE et al (2000) Left ventricular function: correlation of quantitative gated SPECT and MR imaging over a wide range of values. Radiology 217:572-575

21. Bavelaar-Croon CD, Pauwels EK, van der Wall EE (2001) Gated single-photon emission computed tomographic 
myocardial imaging: a new tool in clinical cardiology. Am Heart J 141:383-390

22. Bavelaar-Croon CD, America YG, Atsma DE et al (2001) Comparison of left ventricular function at rest and poststress in patients with myocardial infarction: Evaluation with gated SPECT. J Nucl Cardiol 8:10-18

23. Jenkins C, Bricknell K, Chan J et al (2007) Comparison of two- and three-dimensional echocardiography with sequential magnetic resonance imaging for evaluating left ventricular volume and ejection fraction over time in patients with healed myocardial infarction. Am J Cardiol 99:300-306

24. Sciagra R (2007) The expanding role of left ventricular functional assessment using gated myocardial perfusion SPECT: the supporting actor is stealing the scene. Eur $\mathrm{J}$ Nucl Med Mol Imaging 34:1107-1122

25. Ichikawa Y, Sakuma H, Kitagawa K et al (2003) Evaluation of left ventricular volumes and ejection fraction using fast steady-state cine MR imaging: comparison with left ventricular angiography. J Cardiovasc Magn Reson 5: 333-342

26. Just H, Holubarsch C, Friedburg H (1987) Estimation of left ventricular volume and mass by magnetic resonance imaging: comparison with quantitative biplane angiocardiography. Cardiovasc Intervent Radiol 10:1-4

27. Lethimonnier F, Furber A, Balzer P et al (1999) Global left ventricular cardiac function: comparison between magnetic resonance imaging, radionuclide angiography, and contrast angiography. Invest Radiol 34:199-203

28. Van Rossum AC, Visser FC, Sprenger M et al (1988) Evaluation of magnetic resonance imaging for determination of left ventricular ejection fraction and comparison with angiography. Am J Cardiol 62:628-633

29. Berk F, Isgoren S, Demir H et al (2005) Assessment of left ventricular function and volumes for patients with dilated cardiomyopathy using gated myocardial perfusion SPECT and comparison with echocardiography. Nucl Med Commun 26:701-710

30. Nichols K, Lefkowitz D, Faber T et al (2000) Echocardiographic validation of gated SPECT ventricular function measurements. J Nucl Med 41:1308-1314

31. Kawai J, Tanabe K, Morioka S et al (2003) Rapid freehand scanning three-dimensional echocardiography: accurate measurement of left ventricular volumes and ejection fraction compared with quantitative gated scintigraphy. J Am Soc Echocardiogr 16:110-115

32. Habash-Bseiso DE, Rokey R, Berger CJ et al (2005) Accuracy of noninvasive ejection fraction measurement in a large community-based clinic. Clin Med Res 3:75-82

33. Naik MM, Diamond GA, Pai T et al (1995) Correspondence of left ventricular ejection fraction determinations from two-dimensional echocardiography, radionuclide angiography and contrast cineangiography. J Am Coll Cardiol 25:937-942

34. Arbeille P, Eder V, Casset D et al (2000) Real-time 3-D ultrasound acquisition and display for cardiac volume and ejection fraction evaluation. Ultrasound Med Biol 26: 201-208
35. Kondo C, Fukushima K, Kusakabe K (2003) Measurement of left ventricular volumes and ejection fraction by quantitative gated SPET, contrast ventriculography and magnetic resonance imaging: a meta-analysis. Eur $\mathbf{J}$ Nucl Med Mol Imaging 30:851-858

36. Nichols K, Tamis J, DePuey EG et al (1998) Relationship of gated SPECT ventricular function parameters to angiographic measurements. J Nucl Cardiol 5:295-303

37. Yoshioka J, Hasegawa S, Yamaguchi H et al (1999) Left ventricular volumes and ejection fraction calculated from quantitative electrocardiographic-gated $99 \mathrm{mTc}$-tetrofosmin myocardial SPECT. J Nucl Med 40:1693-1698

38. Gimelli A, Landi P, Marraccini P et al (2008) Left ventricular ejection fraction measurements: accuracy and prognostic implications in a large population of patients with known or suspected ischemic heart disease. Int $\mathbf{J}$ Cardiovasc Imaging. doi:10.1007/s10554-008-9317-1

39. America YG, Bax JJ, Dibbets-Schneider P et al (2005) Evaluation of the Quantitative Gated SPECT (QGS) software program in the presence of large perfusion defects. Int J Cardiovasc Imaging 21:519-529

40. Hunt SA, Abraham WT, Chin MH et al (2005) ACC/AHA 2005 Guideline Update for the Diagnosis and Management of Chronic Heart Failure in the Adult: a report of the American College of Cardiology/American Heart Association Task Force on Practice Guidelines (Writing Committee to Update the 2001 Guidelines for the Evaluation and Management of Heart Failure): developed in collaboration with the American College of Chest Physicians and the International Society for Heart and Lung Transplantation: endorsed by the Heart Rhythm Society. Circulation 112:e154-e235

41. Goldberg LR, Jessup M (2006) Stage B heart failure: management of asymptomatic left ventricular systolic dysfunction. Circulation 113:2851-2860

42. Wang TJ, Evans JC, Benjamin EJ et al (2003) Natural history of asymptomatic left ventricular systolic dysfunction in the community. Circulation 108:977-982

43. Hobbs FD, Roalfe AK, Davis RC et al (2007) Prognosis of all-cause heart failure and borderline left ventricular systolic dysfunction: 5 year mortality follow-up of the Echocardiographic Heart of England Screening Study (ECHOES). Eur Heart J 28:1128-1134

44. Schocken DD, Benjamin EJ, Fonarow GC et al (2008) Prevention of heart failure: a scientific statement from the American Heart Association Councils on Epidemiology and Prevention, Clinical Cardiology, Cardiovascular Nursing, and High Blood Pressure Research; Quality of Care and Outcomes Research Interdisciplinary Working Group; and Functional Genomics and Translational Biology Interdisciplinary Working Group. Circulation 117:2544-2565

45. Chan J, Jenkins C, Khafagi F et al (2006) What is the optimal clinical technique for measurement of left ventricular volume after myocardial infarction? A comparative study of 3-dimensional echocardiography, single photon emission computed tomography, and cardiac magnetic resonance imaging. J Am Soc Echocardiogr 19:192-201 